\title{
Cases for the sole effect of the Indian Ocean Dipole in the rapid phase transition of the El Niño-Southern Oscillation
}

\author{
Jae-Hwi Yoo ${ }^{1,2} \cdot$ Suyeon Moon ${ }^{3,4} \cdot$ Kyung-Ja Ha ${ }^{1,2,3,4}$ (I) $\cdot$ Kyung-Sook Yun ${ }^{3} \cdot J_{\text {June-Yi Lee }}^{1,3,4}$
}

Received: 27 May 2018 / Accepted: 7 May 2020 / Published online: 20 May 2020

(C) The Author(s) 2020

\begin{abstract}
The role of the Indian Ocean sea surface temperature (SST) in the rapid phase transition of the El Niño-Southern Oscillation (ENSO) has received much attention over the last few decades. However, the distinctive role of the Indian Ocean Dipole (IOD) and its underlying dynamics in controlling the rapid transition remains debatable, since it is difficult to isolate the sole effect of the IOD using observation. By conducting model experiments, this study demonstrated that the positive IOD cases could contribute to the rapid phase transition from El Niño to La Niña without the assistance of the Indian Ocean Basin-wide Mode. The westerly wind anomalies over the tropical western Pacific induced not only the El Niño phase via descending Kelvin waves in the equatorial eastern Pacific but also the SST cooling in the off-equatorial western Pacific via ascending Rossby waves. The positive feedback between the upwelling Rossby waves and cool SST maintained the Philippine Sea anticyclone anomalies. The accompanying easterly wind anomalies over the tropical western Pacific triggered upwelling oceanic Kelvin waves, leading to the occurrence of La Niña. This study shows the possible role of the IOD in the rapid phase transition of ENSO.
\end{abstract}

\section{Introduction}

The El Niño-Southern Oscillation (ENSO), a well-known coupled atmosphere-ocean phenomenon, is characterized by the inter-annual fluctuation of sea surface temperature (SST) and atmospheric pressure over the tropical Pacific. Due to strong socioeconomic impacts, many researchers have sought

Key points - The positive IOD cases can cause westerly wind over the tropical WP, which changes to the easterly wind via a strong Philippine Sea anticyclone (PSAC).

- The PSAC triggers a prolonged strong easterly wind over the tropical WP, with an upwelling oceanic Kelvin wave, which favors the La Niña. - The cases of rapid phase transition from El Niño to La Niña can be generated solely by the effects of the positive Indian Ocean Dipole.

Kyung-Ja Ha

kjha@pusan.ac.kr

1 Research Center for Climate Sciences, Pusan National University, Busan 46241, South Korea

2 Department of Atmospheric Sciences, Pusan National University, Busan 46241, South Korea

3 Center for Climate Physics, Institute for Basic Science, Busan 46241, South Korea

4 Department of Climate System, Pusan National University, Busan 46241, South Korea to understand the interaction between ENSO and other oceans, and its underlying dynamics (Annamalai et al. 2005; Klein et al. 1999; Kug et al. 2006; Wu and Kirtman 2004). Inter-basin variability suggested by Izumo et al. $(2010,2016)$ is a possible mechanism for the transition of well-known ENSO oceanic internal dynamics, initially suggested by Weisberg and Wang (1997), and oceanic delayed negative feedback related to oceanic wave reflections at both Pacific Ocean boundaries (Battisti and Hirst 1989; Picaut et al. 1997; Suarez and Schopf 1988). Particular focus has been placed on the effect of the major Indian Ocean (IO) modes - the Indian Ocean Basin-wide Mode (IOBM) and Indian Ocean Dipole (IOD) — on ENSO behavior (Dayan et al. 2015; Ha et al. 2017; Izumo et al. 2010; Izumo et al. 2016; Jourdain et al. 2016; Kug and Kang 2006; Luo et al. 2010; Ohba and Ueda 2007; Saji et al. 1999; Xie et al. 2009).

Many previous studies have emphasized the critical role of the IOBM in the ENSO transition. The positive IOBM, which is strongly connected with the positive phase of ENSO, induces anomalous easterly winds over the tropical western Pacific (WP; Dayan et al. 2015; Ohba and Ueda 2007). The upwelling oceanic Kelvin wave responses to these anomalous easterly winds then accelerates the ENSO phase change. Recent studies have emphasized the role of the IOD in modulating ENSO development and its phase transition (Izumo et al. 2010; Jourdain et al. 2016; Luo et al. 2010). Izumo 
Fig. 1 Second EOF pattern of monthly SST anomalies over the Indian Ocean (unit, ${ }^{\circ} \mathrm{C}$ )

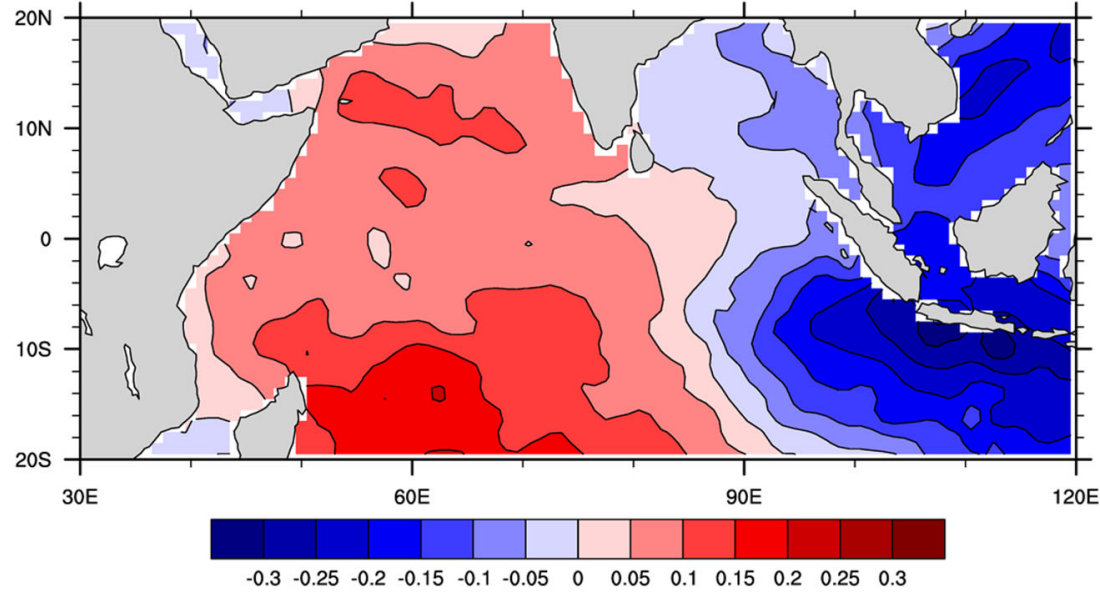

et al. (2010) proposed the relationship between a negative IOD in one year and the following year's El Niño. However, Dayan et al. (2015) reported that only the IOBM could trigger significant SST modulation in the tropical Pacific, based upon the results from their numerical experiments.

Nonetheless, the IOD might play an important role in modulating the tropical Pacific SST, because the IOD can amplify the effects of the following IOBM on ENSO phase change by triggering abrupt zonal wind changes over the tropical WP (Izumo et al. 2016). Partial correlations/regressions have shown that the IOD on its own can influence the ENSO phase transition by affecting the western Pacific zonal wind stress and its temporal variations. However, a coupled general circulation model (CGCM) experiment to verify this in the Pacific has not been undertaken. Ha et al. (2017) confirmed that the biennial tendency of ENSO is dominant when it accompanies the co-occurring IOD following the IOBM. The study also reported evidence for the sole IOD effect on ENSO rapid phase transition, using analyses of phase five of the Coupled Model Intercomparison Project (CMIP5) dataset.
IOD-ENSO-(IOBM)

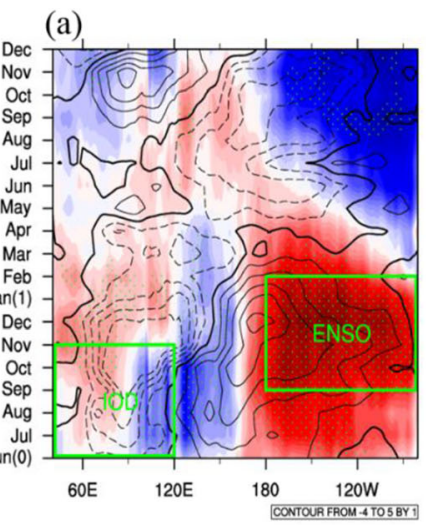

(d)

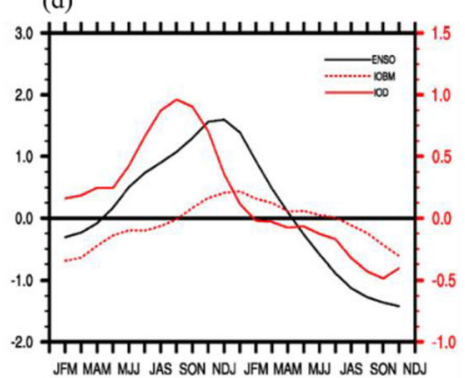

(IOD)-ENSO-IOBM

(b)

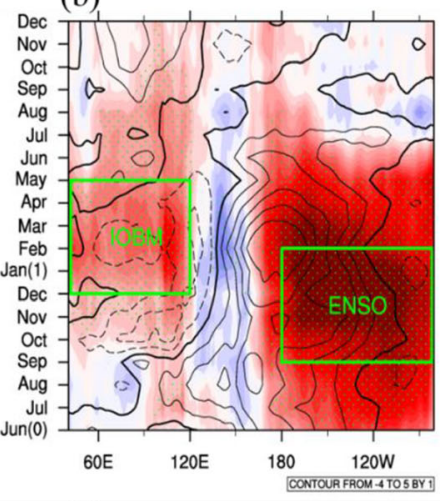

(e)

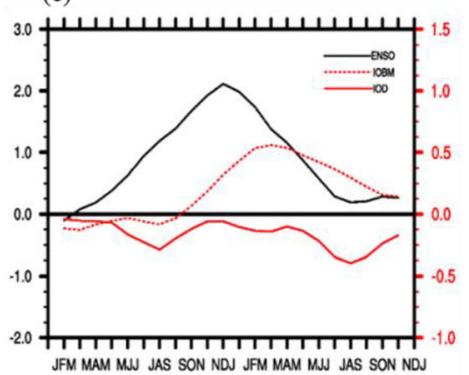

(IOD) -ENSO- (IOBM)

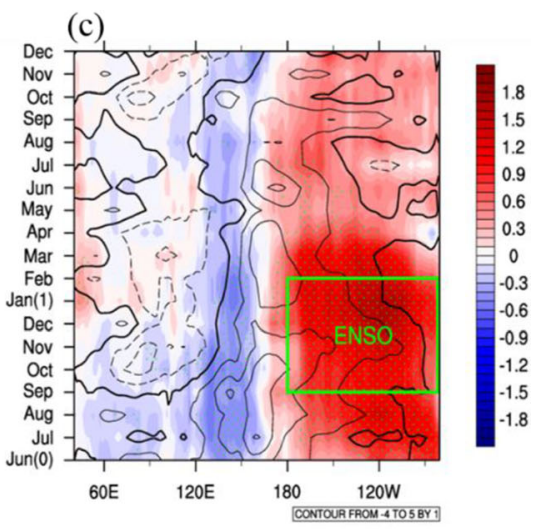

(f)

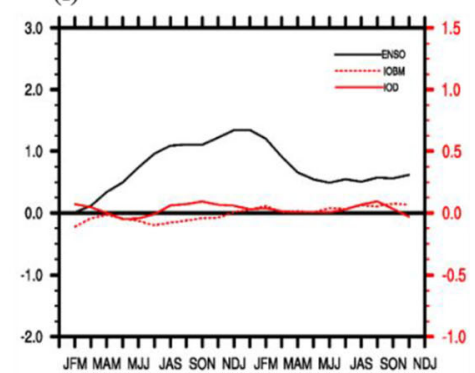

Fig. 2 a-c Composite mean difference of $5^{\circ} \mathrm{S}-5^{\circ} \mathrm{N}$ averaged SST (shading, ${ }^{\circ} \mathrm{C}$ ) and $850 \mathrm{hPa}$ zonal wind (contour, $\mathrm{ms}^{-1}$ ) between El Niño and La Niña years for IOD-ENSO-(IOBM), (IOD)-ENSO-IOBM, and (IOD)-ENSO-(IOBM) using HadISST. Stippling denotes confidence level of above 95\% using two-tailed Student's $t$ test. Black bold contours represent zero, and dashed contours indicate negative value (easterly winds). $\mathbf{d}-\mathbf{f}$ Composite mean difference of the indices for ENSO (black/ solid), IOBM (red/dash), and IOD (red/solid) between positive and negative years for each ENSO type 
Since the numerical experiment of Dayan et al. (2015) did not involve the Bjerknes feedback because of its two-tier approach, reconsideration of the role of the IOD in tropical Pacific SST modulation in the atmosphere-ocean coupled system should be reconsidered.

The objective of this study was to investigate whether the IOD could accelerate the ENSO phase transition without the assistance of the following IOBM, as suggested in several previous studies and by its underlying dynamics. To do this, isolating the effect of the IOD on the tropical Pacific SST from the IOBM was isolated. This study used multiple linear regression analysis with reconstructed data and conducted numerical experiments using the CGCM.

\section{Data and method}

Hadley Centre SST data (HadISST, Rayner et al. 2003) were used in the multiple linear regression analysis. The horizontal resolution of the datasets was $1^{\circ}$ by $1^{\circ}$. SST data for 1900-2100 were analyzed. Three SST indices were used to classify the IOD, ENSO, and IOBM (Ha et al. 2017). The IOD index was defined (Saji et al. 1999) as the difference between the SST anomalies in the western Indian Ocean (WIO) $\left(5^{\circ} \mathrm{S}-5^{\circ} \mathrm{N}, 50^{\circ} \mathrm{E}-70^{\circ} \mathrm{E}\right)$ and eastern Indian Ocean (EIO) $\left(10^{\circ} \mathrm{S}-0^{\circ}, 90^{\circ} \mathrm{E}-110^{\circ} \mathrm{E}\right)$. The ENSO and IOBM indices were calculated using the area average of the SST anomalies over the Niño 3 region $\left(5^{\circ} \mathrm{S}-5^{\circ} \mathrm{N}, 150^{\circ} \mathrm{W}-90^{\circ} \mathrm{W}\right)$ and across the IO $\left(20^{\circ} \mathrm{S}-20^{\circ} \mathrm{N}, 40^{\circ} \mathrm{E}-120^{\circ} \mathrm{E}\right)$ (Chu et al. 2014; Yun et al. 2013). By considering the seasonal characteristics of the three events, specific seasonal-averaged indices were used in the multiple linear regression analysis, i.e., September-November of the first year $(\mathrm{SON}(0))$ for the IOD, the following December-February $(\mathrm{D}(0) \mathrm{JF}(1))$ for ENSO, and the following March-May (MAM(1)) for the IOBM (Ha et al. 2017). Reanalysis data from the European Centre for Medium-Range Weather Forecast (ECMWF) twentieth century reanalysis (ERA-20C) were used in this study (Poli et al. 2016). The Simple Ocean Data Assimilation version 2.2.4 (SODA) ocean reanalysis for $20^{\circ} \mathrm{C}$ thermocline depth (D20) data was used to compare the model results.

A suite of CGCM experiments was conducted. The coupled model consisted of three components, i.e., (1) The Parallel Ocean Program (POP, v2.0) model was used for the ocean part (Dukowicz and Smith 1994; Smith et al. 1992), (2) Max Planck Institute (MPI) ECHAM (v4.6) was used for the atmospheric part (Roeckner et al. 1996), and (3) the Ocean-Atmosphere-Sea Ice-Soil (OASIS, v3.0) was used as the coupler (Valcke et al. 2003). This model was named POEM (POP-OASIS-ECHAM model) for convenience, and detailed information has been provided by Xiang et al. (2012). With respect to the experimental design, the control run (CTRL) was a fully coupled run of 40 years, after 10 years of spin-up. In addition, 20 experiments, each with a run of two years run, with the IOD forcing in $\mathrm{SON}(0)$, were conducted using 20 initial states extracted from the CTRL. The second mode of the empirical orthogonal
Table 1 Years selected for IOD-ENSO-(IOBM), (IOD)-ENSOIOBM, and (IOD)-ENSO-(IOBM) from 1900 to 2010

\begin{tabular}{|c|c|c|}
\hline & El Niño & La Niña \\
\hline IOD-ENSO-(IOBM) & $\begin{array}{c}1904 / 1905 \\
1951 / 1952 \\
1963 / 1964 \\
1965 / 1966 \\
1994 / 1995 \\
2006 / 2007\end{array}$ & $\begin{array}{c}1906 / 1907, \\
1909 / 1910, \\
1910 / 1911, \\
1921 / 1922, \\
1984 / 1985, \\
1996 / 1997, \\
1998 / 1999, \\
2005 / 2006\end{array}$ \\
\hline (IOD)-ENSO-IOBM & $\begin{array}{c}1905 / 1906 \\
1911 / 1912 \\
1913 / 1914 \\
1914 / 1915 \\
1918 / 1919 \\
1930 / 1931 \\
1939 / 1940 \\
1940 / 1941 \\
1941 / 1942 \\
1957 / 1958 \\
1968 / 1969 \\
1969 / 1970 \\
2009 / 2010\end{array}$ & $\begin{array}{c}1920 / 1921, \\
1924 / 1925, \\
1949 / 1950, \\
1955 / 1956, \\
1962 / 1963, \\
967 / 1968, \\
1970 / 1971, \\
1973 / 1974, \\
1985 / 1986, \\
1988 / 1989, \\
1999 / 2000, \\
2007 / 2008\end{array}$ \\
\hline (IOD)-ENSO-(IOBM) & $\begin{array}{c}1919 / 1920 \\
1976 / 1977 \\
1991 / 1992 \\
2003 / 2004\end{array}$ & $\begin{array}{c}1908 / 1909, \\
1915 / 1916, \\
1922 / 1923, \\
1934 / 1935, \\
1936 / 1937, \\
1938 / 1939, \\
1944 / 1945, \\
1995 / 1996\end{array}$ \\
\hline
\end{tabular}

function (EOF) of SST anomalies over the tropical IO $\left(30^{\circ} \mathrm{E}-\right.$ $120^{\circ} \mathrm{E}, 20^{\circ} \mathrm{S}-20^{\circ} \mathrm{N}$ ) was used for the IOD SST forcing (Fig. 1). The EOF1 mode over the IO displayed warming patterns over a wide area of this ocean, which was defined by IOBM in a previous study (Ha et al. 2017). The two leading EOF modes from POEM model for a run of 50 years were generally well displayed (not shown). To prescribe the IOD intensity as strong as the SON SST anomalies based on positive IOD year cases, the SST forcing pattern, i.e., the EOF2 mode, was increased by a factor of three. This experiment was named EXP IOD. The effect of the IOD was calculated by subtracting the average of the CTRL from that of the EXP IOD. In addition, this experiment allowed atmosphereocean coupling across the tropical oceans. Thus, the Bjerknes feedback could play an important role in both the response of the Pacific to the IOD and the IOD lifecycle.

\section{Observational evidence for the role of the sole IOD on ENSO rapid phase transition}

To determine the effect of the sole IOD on ENSO rapid phase transition, a composite analysis was performed with the IOD, ENSO, and IOBM (Fig. 2), which come from the composite 
(a) $\beta_{I O D}$

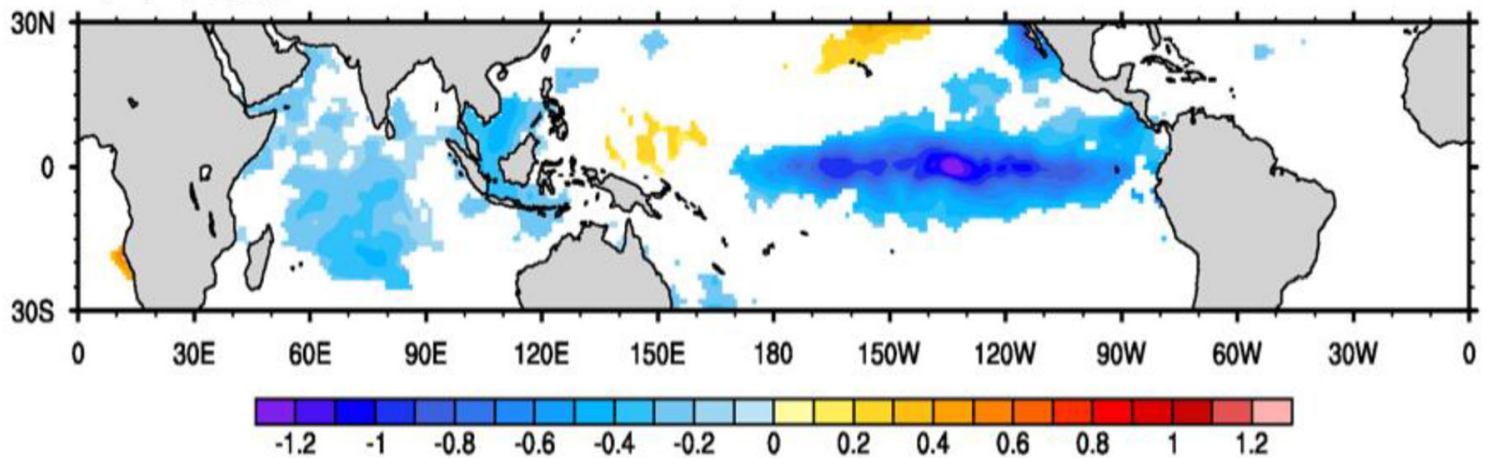

(b) $\beta_{I O B M}$

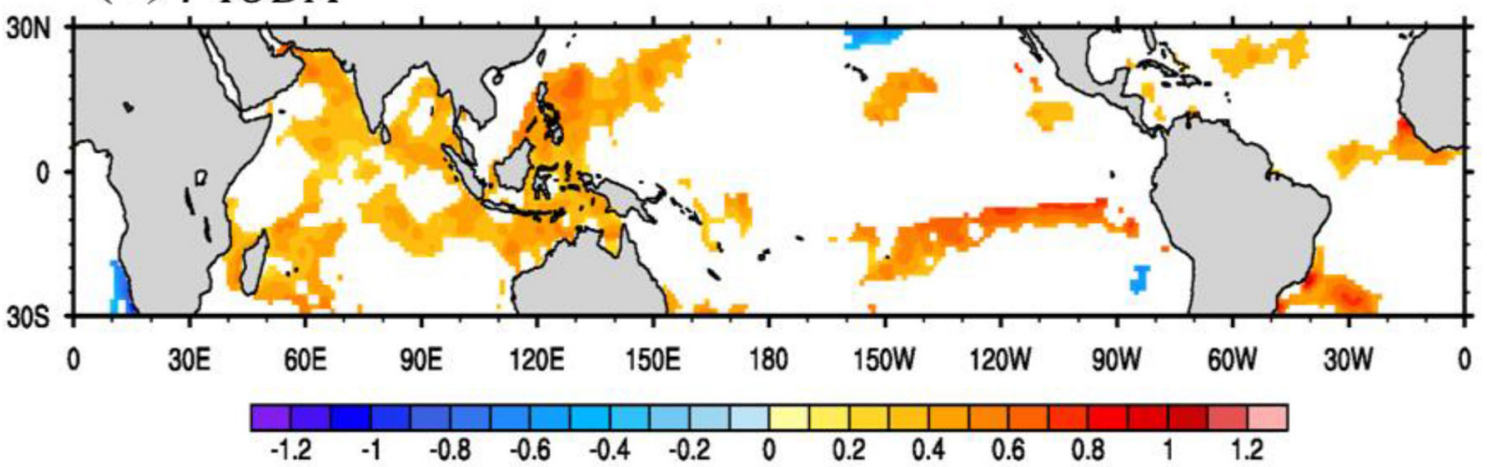

Fig. 3 Multiple linear regression coefficients for the (a) IOD during SON(0) and (b) IOBM during MAM(1), regressed on SST in D(1)JF(2). Values with confidence levels above $95 \%$ are plotted

difference between El Niño and La Niña years from Table 1. Hereafter, the IOD, ENSO, and IOBM denote their positive phases, and parentheses are used to indicate the existence of an event. For example, "IOD-ENSO-(IOBM)" denotes ENSO with the preceding IOD, but no subsequent IOBM. Each event was classified as 0.5 standard deviations of each index for 1900-2010 period and introduced in the manuscript with the specific seasonal mean, namely $\mathrm{SON}(0)$ for the IOD, $\mathrm{D}(0) \mathrm{JF}(1)$ for the ENSO, and MAM(1) for the IOBM. The left panels in Fig. 2 show the cases with the IOD and ENSO (without IOBM), the middle panels show the cases with ENSO and IOBM (without IOD), and the right panels show the cases with only ENSO. Notably, the phase transitions with the IOD cases (Fig. 2 a and d) are faster than those without the
Fig. 4 a-e Difference in seasonalaveraged SST (shading, ${ }^{\circ} \mathrm{C}$ ) and $1000 \mathrm{hPa}$ wind (vector, $\mathrm{ms}^{-1}$ ) between EXP IOD and CTRL experiments. Twenty EXP IOD ensemble mean minus each twoyear mean of 20 CTRL cases is used. Yellow and white contours denote $95 \%$ and $90 \%$ confidence levels for SST, respectively. The black and green vectors respectively denote more than $95 \%$ and $90 \%$ significance values for wind. f Same as (a-e) but for areaaveraged SST over IOD, ENSO, and IOBM regions
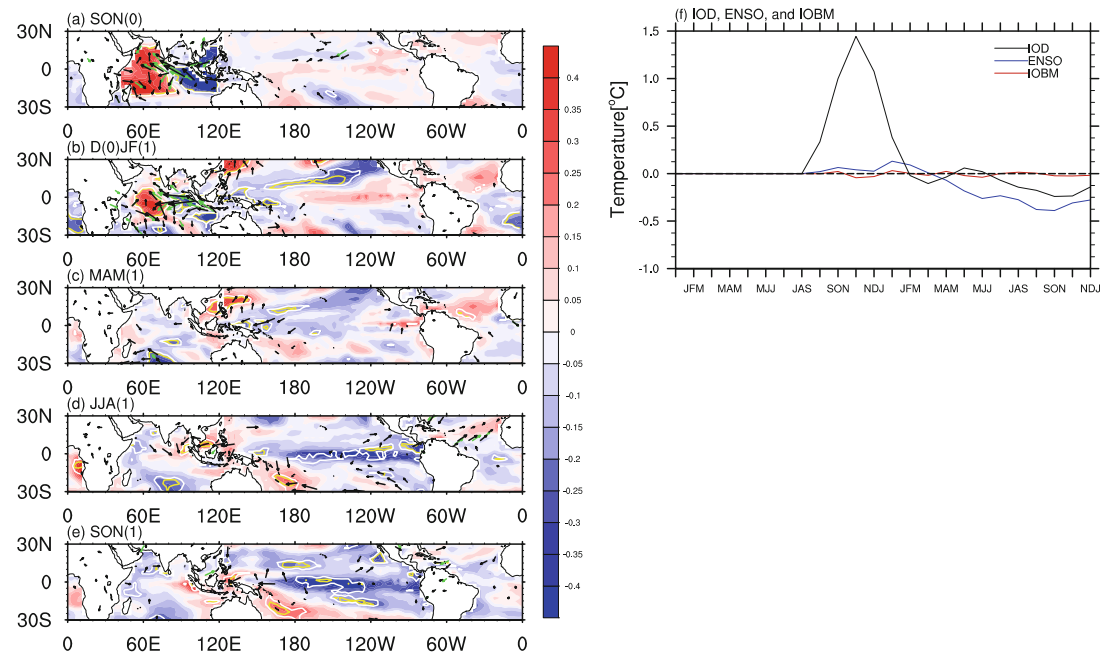
Fig. 5 Difference in SST over the Niño 3 region between 20 members of EXP_IOD and CTRL mean. Thick orange line denotes mean difference between EXP_IOD and CTRL

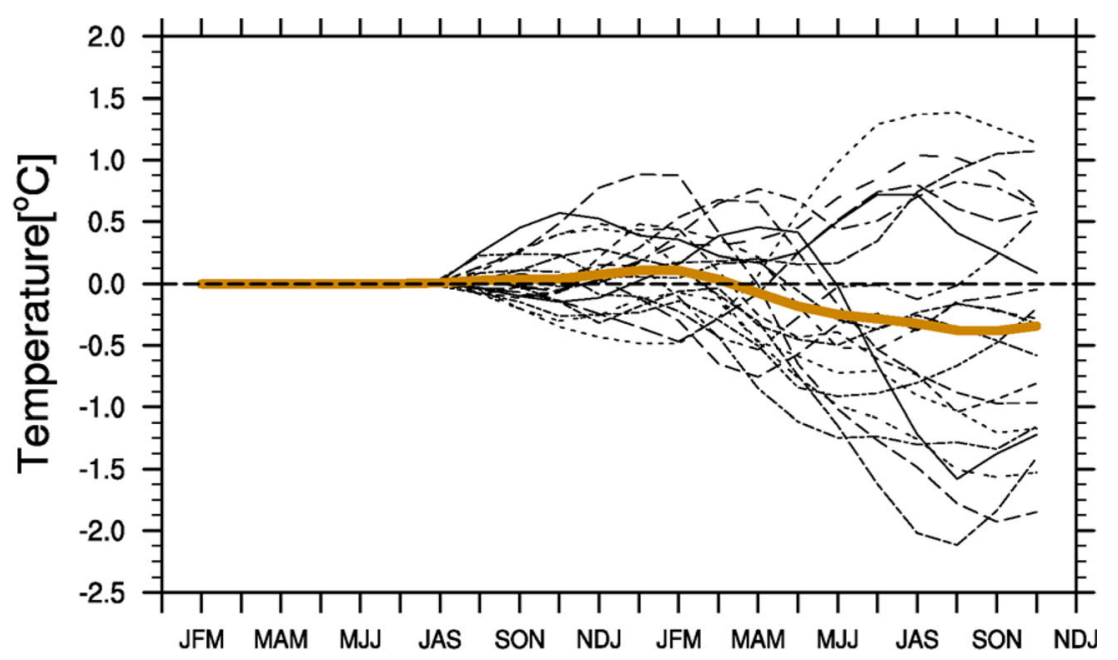

IOD. The other types tend to retain their original phase or become a neutral state (Fig. 2b, c, e, and f). Thus, the biennial tendency of the ENSO is more obvious in the IODaccompanying ENSO than the IOBM-combined or pure ENSO.

To confirm the respective effects of the IOD and IOBM on the following tropical Pacific SST modulation, multiple linear regression analysis was conducted:

$$
\begin{aligned}
\operatorname{SSTD}_{(1) J F(2)}= & \beta_{I O D} \times I O D_{S O N(0)}+\beta_{I O B M} \\
& \times I O B M_{M A M(1)}+C
\end{aligned}
$$

where IODSON(0) and IOBMMAM(1) represent the IOD and IOBM indices averaged for the specific seasons. Because of the strong linear relationship between the ENSO and the IOBM as well as the multicollinearity problem, the ENSO index for $\mathrm{D}(0) \mathrm{JF}(1)$ was excluded from this analysis. The results of the multiple linear regression showed the distinct effect of the IOD in SON(0) on the following SST (approximately 15 months later) over the tropical central Pacific (CP) to eastern Pacific (EP) (Fig. 3a). However, the effect of the IOBM in MAM(1) on the following D(1)JF(2) SST in the tropical Pacific was lower (Fig. 3b). These results suggested that the IOD was more responsible for the external forcing of the IO on the tropical Pacific SST anomalies than the IOBM was. Thus, the IOD may influence the tropical Pacific SST without the assistance of the following IOBM, as suggested in a previous study (Izumo et al. 2010).

However, the possibility that the IOD was not physically connected to the tropical Pacific SST remained, because different characteristics of individual ENSO events, rather than the IOD, could modulate the tropical Pacific SST (e.g., peak season of the ENSO). Accordingly, the results of the statistical analysis did not guarantee the physical influence of the positive (negative) IOD on the following SST cooling (warming) over the tropical CP to EP. Therefore, idealized CGCM experiments were conducted to determine whether the sole IOD influenced SST over the tropical Pacific under the same initial conditions, with the exception of the IOD.

\section{Role of the positive IOD in driving the central and eastern Pacific cooling}

In the EXP_IOD, the positive IOD (pIOD) substantially influences SST cooling over the tropical CP to EP, with a lag time of one year (Fig.4a-e). The pIOD starts in $\mathrm{SON}(0)$, decays in $\mathrm{D}(0) \mathrm{JF}(1)$, and completely disappears in MAM(1). Moreover, low-level easterly winds over the tropical WP are induced in MAM(1), which could induce upwelling oceanic Kelvin waves (Fig. 4c). Accordingly, in the tropical CP and EP, significant cooling of the SST starts in June-August JJA(1) and intensifies in the following season (Fig. $4 \mathrm{~d}$ and e). Among 20 ensemble members, nine cases (45\%) display a cooling effect lower than $-0.5^{\circ} \mathrm{C}$ over the Niño 3 region in SON(1) (Fig. 5). Note that there are no significant anomalies in the subsequent IOBM (Fig. 4f). This result demonstrates that the IOD could physically influence the tropical Pacific SST without the influence of the following IOBM. In light of the double forcing experiment, the cooling effects over the Niño 3 region occur in approximately $40 \%$ cases (not shown).

Monthly variations in the SST, zonal wind, upper level zonal current $(\sim 100 \mathrm{~m})$, oceanic thermocline depth, and precipitation over the tropical and off-equatorial region are also investigated (Fig. 6). In December of the first year, westerly winds arise over the tropical WP as shown by Izumo et al. (2010). This suggests the impact of the pIOD on the development of the following El Niño (Luo et al. 2010). The westerly winds over the western CP in December (Fig. 6f) are seemingly related to reduced precipitation over the WP and 
Hovmoller diagrams [EXP_IOD - CTRL]
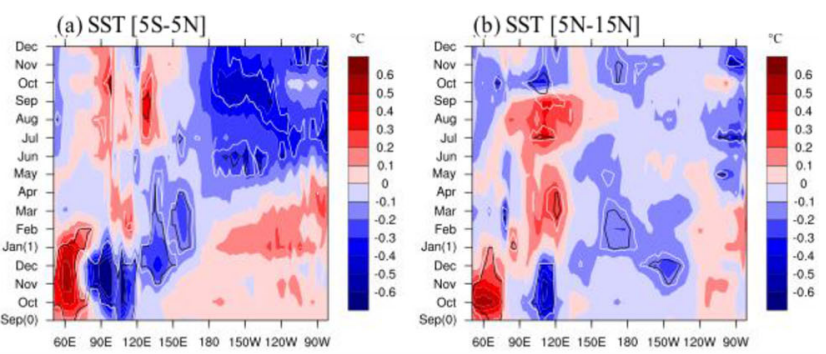

(c) $\mathrm{D} 20[5 \mathrm{~S}-5 \mathrm{~N}]$
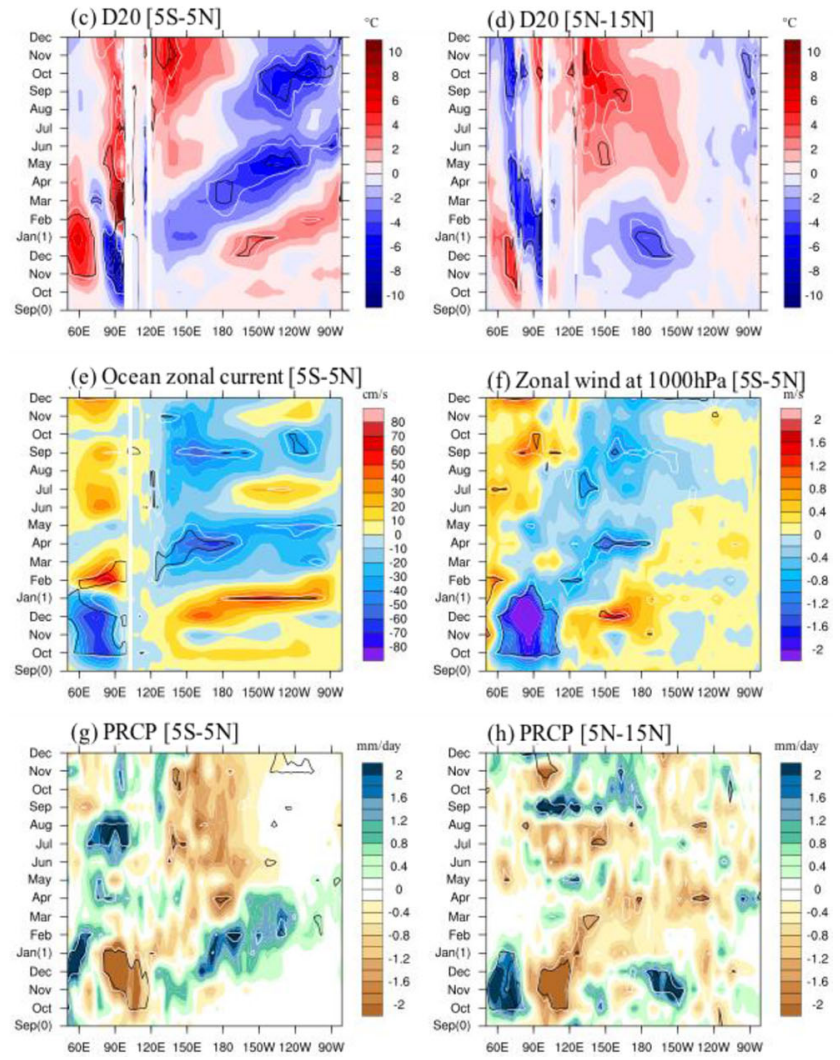

Fig. 6 Difference in SST between EXP IOD and CTRL averaged over (a) $5^{\circ} \mathrm{S}-5^{\circ} \mathrm{N}$ and (b) $5^{\circ} \mathrm{N}-15^{\circ} \mathrm{N}$. (c-d) and (g-h) are the same as (a) and (b) but showing oceanic $20^{\circ} \mathrm{C}$ isotherm depth (D20) and precipitation (PRCP), respectively. (e-f) is the same as (a) but for oceanic zonal current and $1000 \mathrm{hPa}$ zonal wind. Black and white contours denote $95 \%$ and $90 \%$ confidence levels, respectively

enhanced precipitation over the CP (Fig. 6g). Note that the westerly winds abruptly disappeared and changed to easterly winds some months later (Fig. 6f).

The Philippine Sea anticyclone (PSAC) played an important role in the propagation of the easterly winds over the tropical WP in the boreal spring of the decaying IOD year. When the westerly winds over the tropical WP (Fig. 6f) triggered downwelling oceanic Kelvin waves in December(0) (Fig. 6c), it also initiated westerly propagating upwelling Rossby waves over the northern off-equatorial region (Fig. 6d). These oceanic waves can cool SST over the offequatorial WP (Fig. 6b). Such cooling is known to intensify the PSAC by suppressing atmospheric convection (Fig. 6h).

The positive feedback between the atmospheric Rossby wave response and cool SST maintains the PSAC anomalies also (Li et al. 2006; Wang et al. 2000). Precipitation anomalies (Fig. 6g) from winter to spring represent the associations with the enhanced easterly winds from February, and accordingly, the eastward propagation of thermocline depths (Fig. 6c). Figure 7 a shows the SST cooling over the WP, with strong PSAC and increased northeasterly winds in the right branch of the anticyclone in March(1). Strong PSAC then triggers upwelling oceanic Kelvin waves over the equator via easterly wind anomalies, which are affected by the equatorward side of the PSAC, over the tropical WP.

The resultant upwelling oceanic Kelvin waves then arise, and the Kelvin wave associated with easterly zonal currents also starts over the tropical WP (Fig. 6c and e). Accordingly, the SST cooling over the CP occurred from approximately May(1), when the Kelvin wave reached the CP (Fig. 6a). This cooling causes more cooling in the following seasons via the Bjerknes feedback because the atmospheric response to a given SST forcing over the $\mathrm{CP}$ is strong owing to the climatologically warm SST over the region (Spencer 2004). More SST cooling with the strong easterly winds over the $\mathrm{CP}$ in the following seasons confirms that the Bjerknes feedback amplifies the initial Pacific SST response and triggers the La Niña-like SST and thermocline patterns (Wang and Zhang 2002; Fig. 6a and c). In general, these processes are likely associated with the WP oscillator theory (Weisberg and Wang 1997).

\section{Summary and discussion}

This study investigates the role of the sole IOD in ENSO rapid phase transition. Multiple linear regression analysis indicates that the ENSO co-occurring IOD could trigger a rapid phase transition of the ENSO without assistance from the following IOBM, as suggested in several previous studies. To examine the physical connection between the IOD and SST changes over the tropical CP to EP, idealized CGCM experiments are also conducted with fully coupled atmosphere-ocean conditions, which allow the Bjerknes feedback in the Pacific and Indian Oceans. The experiments show that the pIOD initially induces low-level westerly wind over the tropical WP in December(0). The westerly winds affect the warm SST over tropical EP. Furthermore, it initiates upwelling oceanic Rossby waves in the northern off-equatorial WP. These waves cool down the SST over the northern off-equatorial WP, triggering the strong PSAC. Consequently, the easterly winds arise in the tropical WP in March(1). These low-level easterly winds induce ascending oceanic Kelvin waves in the tropical WP. As a result, the cold SST in the tropical CP and EP starts in May(1). This cooling is further strengthened by the easterly winds over the tropical $\mathrm{CP}$ in the following seasons, highlighting the role of the Bjerknes feedback. 
Fig. 7 Mean differences in SST (shading, ${ }^{\circ} \mathrm{C}$ ), $1000 \mathrm{hPa}$ rotational wind (vector, $\mathrm{ms}^{-1}$ ) with more than $95 \%$ confidence level, and stream function at $1000 \mathrm{hPa}$ (green contour, $10^{6} \mathrm{~m}^{2} \mathrm{~s}^{-1}$ with interval of 0.2) between EXP IOD and CTRL experiments in (a) $\operatorname{March}(1)$ and (b) April(1). Bold green contour denotes zero. White and black contours respectively denote $90 \%$ and the $95 \%$ confidence levels

Fig. 8 Same as Fig. 4 a-e but for the negative IOD experiment

\section{[EXP_IOD - CTRL]}

(a) MAR(1)

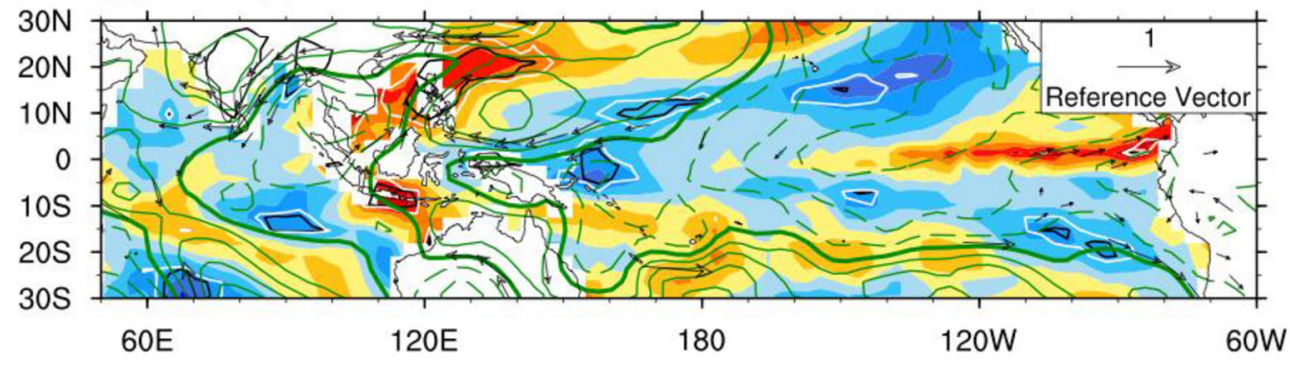

(b) APR(1)
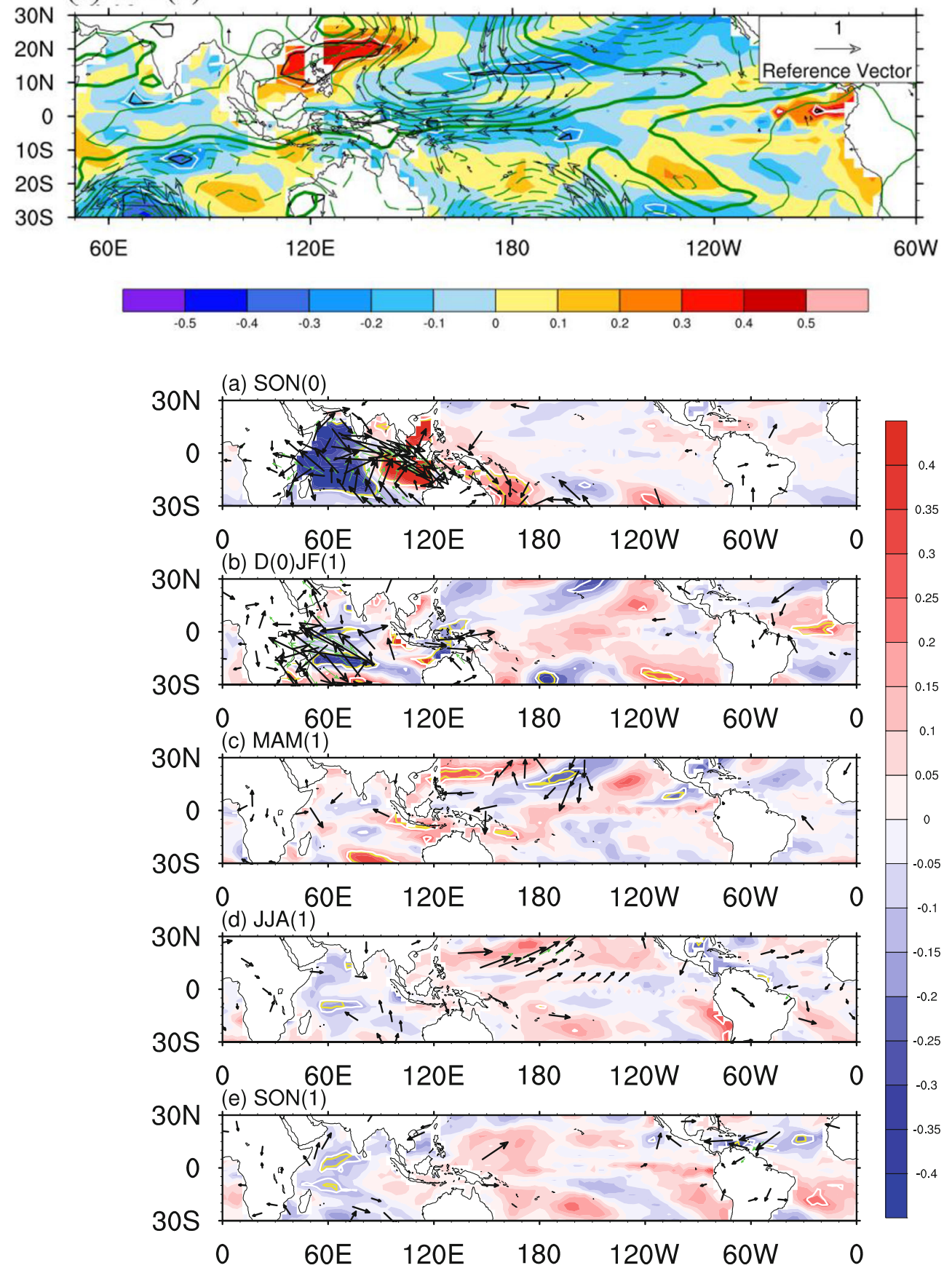
Several issues warrant further investigation. Some studies have reported that the oceanic channel process between the IO and WP is distinctive when the IOD co-occurs with the ENSO, whereas others have reported that the oceanic bridge is weak (Izumo et al. 2016; Schwarzkopf and Böning 2011; Zhao et al. 2016). Accordingly, the contributions of the atmospheric bridge and oceanic channel to the IOD effect on tropical Pacific SST should be investigated in greater detail. In addition, multi-decadal changes in the Indo-Pacific inter-basin coupling (Dong and McPhaden 2017; Han et al. 2014a, b) should be examined. A warmer state is one possible cause of the weakened connection between the IOD and ENSO over the past two decades (Ham et al. 2017). In this sense, multi-decadal changes in the IODENSO interaction may account for the discrepancies in the effects of the IOD on ENSO transition between the relatively long period of the CMIP5 and the relatively short period of the reconstructed data of Ha et al. (2017).

The reason for the negative version of EXP_IOD showing no significant SST warming in the tropical Pacific also needs a further investigation (Fig. 8), as shown by statistical evidence for asymmetrical in ENSO-IOD interactions (Lestari and Koh 2016). Despite these remaining questions and scope for further research, this study improves the knowledge of the IndoPacific inter-basin coupling and ENSO predictability, by providing confirmatory results from observations and modeling regarding the sole IOD effect on ENSO phase transition without the aid of the following IOBM.

Funding information This study was supported by the Korea Ministry of Environment (MOE) as "graduate School specialized in Climate Change" and the GRL grant from the National Research Foundation (NRF) of the Korean Government (MEST 2011-0021927).

Data availability All the CGCM experiment data used in this study are available from the corresponding author upon request (e-mail: kjha@pusan.ac.kr). The HadISST data are available from http://www. metoffice.gov.uk/hadobs/hadisst/data/ download.html. The ERA-20C data are available from http://www.ecmwf.int. The Simple Ocean Data Assimilation version 2.2.4 (SODA) ocean reanalysis is provided by http://dsrs.atmos.umd.edu/DATA/soda_2.2.4/.

\section{Compliance with ethical standards}

Competing interests The authors declare that they have no conflict of interest.

Open Access This article is licensed under a Creative Commons Attribution 4.0 International License, which permits use, sharing, adaptation, distribution and reproduction in any medium or format, as long as you give appropriate credit to the original author(s) and the source, provide a link to the Creative Commons licence, and indicate if changes were made. The images or other third party material in this article are included in the article's Creative Commons licence, unless indicated otherwise in a credit line to the material. If material is not included in the article's Creative Commons licence and your intended use is not permitted by statutory regulation or exceeds the permitted use, you will need to obtain permission directly from the copyright holder. To view a copy of this licence, visit http://creativecommons.org/licenses/by/4.0/.

\section{References}

Annamalai H, Xie SP, McCreary JP, Murtugudde R (2005) Impact of Indian Ocean sea surface temperature on developing El Niño. J Clim 18(2):302-319

Battisti DS, Hirst AC (1989) Interannual variability in the tropical atmosphere-ocean model: influence of the basic state, ocean geometry and nonlineary. J Atmos Sci 45:1687-1712

Chu JE, Ha KJ, Lee JY, Wang B, Kim BH, Chung CE (2014) Future change of the Indian Ocean basin-wide and dipole modes in the CMIP5. Clim Dyn 43(1-2):535-551

Dayan H, Izumo T, Vialard J, Lengaigne M, Masson S (2015) Do regions outside the tropical Pacific influence ENSO through atmospheric teleconnections? Clim Dyn 45(3-4):583-601

Dong L, McPhaden J (2017) Why has the relationship between Indian and Pacific Ocean decadal variability changed in recent decades? J Clim 30(6):1971-1983

Dukowicz JK, Smith RD (1994) Implicit free-surface method for the Bryan-Cox-Semtner ocean model. J Geophys Res Oceans 99(C4): 7991-8014

Ha KJ, Chu JE, Lee JY, Yun KS (2017) Interbasin coupling between the tropical Indian and Pacific Ocean on interannual timescale: observation and CMIP5 reproduction. Clim Dyn 48(1-2):459-475

Ham YG, Choi JY, Kug JS (2017) The weakening of the ENSO-Indian Ocean Dipole (IOD) coupling strength in recent decades. Clim Dyn 49:249-261

Han W, Meehl GA, Hu A, Alexander MA, Yamagata T, Yuan D, Ishii M, Pegion P, Zheng J, Hamlington BD, Quan XW, Leben RR (2014a) Intensification of decadal and multidecadal sea level variability in the western tropical Pacific during recent decades. Clim Dyn 43: 1357-1379. https://doi.org/10.1007/s00382-013-1951-1

Han W, Vialard J, McPhaden MJ, Lee T, Masumoto Y, Feng M, de Ruijter WPM (2014b) Indian ocean decadal variability: a review. Bull Am Meteorol Soc 95:1679-1703. https://doi.org/10.1175/ BAMS-D-13-00028.1

Izumo T, Vialard J, Lengaigne M, de Boyer Montegut C, Behera SK, Luo $\mathrm{JJ}$ et al (2010) Influence of the state of the Indian Ocean Dipole on the following year's El Niño. Nat Geosci 3(3):168-172

Izumo T, Vialard J, Dayan H, Lengaigne M, Suresh I (2016) A simple estimation of equatorial Pacific response from windstress to untangle Indian Ocean Dipole and Basin influences on El Niño. Clim Dyn 46(7-8):2247-2268

Jourdain NC, Lengaigne M, Vialard J, Izumo T, Gupta AS (2016) Further insights on the influence of the Indian Ocean dipole on the following year's ENSO from observations and CMIP5 models. J Clim 29(2): 637-658

Klein SA, Soden BJ, Lau NC (1999) Remote sea surface temperature variations during ENSO: evidence for a tropical atmospheric bridge. J Clim 12(4):917-932

Kug JS, Kang IS (2006) Interactive feedback between ENSO and the Indian Ocean. J Clim 19(9):1784-1801

Kug JS, Li T, An SI, Kang IS, Luo JJ, Masson S, Yamagata T (2006) Role of the ENSO-Indian Ocean coupling on ENSO variability in a coupled GCM. Geophys Res Lett 33:L09710

Lestari RK, Koh TY (2016) Statistical evidence for asymmetry in ENSOIOD interactions. Atmos Ocean 54(5):498-504

Li T, Liu P, Fu X, Wang B, Meehl GA (2006) Spatiotemporal structures and mechanisms of the tropospheric biennial oscillation in the IndoPacific warm ocean regions. J Clim 19(13):3070-3087

Luo JJ, Zhang R, Behera SK, Masumoto Y, Jin FF, Lukas R, Yamagata T (2010) Interaction between El Nino and extreme Indian ocean dipole. J Clim 23(3):726-742

Ohba M, Ueda H (2007) An impact of SST anomalies in the Indian Ocean in acceleration of the El Niño to La Niña transition. J Meteor Soc Jpn 85(3):335-348 
Picaut J, Masia F, du Penhoat Y (1997) An advective-reflective conceptual model for the oscillatory nature of the ENSO. Science 277:663666

Poli P, Hersbach H, Dee DP, Berrisford P, Simmons AJ, Vitart F, Laloyaux P, Tan DGH, Peubey C, Thépaut JN, Trémolet Y, Hólm EV, Bonavita M, Isaksen L, Fisher M (2016) ERA-20C: an atmospheric reanalysis of the twentieth century. J Clim 29(11):40834097

Rayner NA, Parker DE, Horton EB, Folland CK, Alexander LV, Rowell DP et al (2003) Global analyses of sea surface temperature, sea ice, and night marine air temperature since the late nineteenth century. $\mathrm{J}$ Geophys Res Atmos 108(D14)

Roeckner E, Arpe L, Bengtsson L, Christoph M, Claussen L, Esch M et al (1996) The atmospheric general circulation model ECHAM4: model description and simulation of present-day climate. MPI Report 218

Saji NH, Goswami BN, Vinayachandran PN, Yamagata T (1999) A dipole mode in the tropical Indian Ocean. Nature 401(6751):360 363

Schwarzkopf FU, Böning CW (2011) Contribution of Pacific wind stress to multi-decadal variations in upper-ocean heat content and sea level in the tropical south Indian Ocean. Geophys Res Lett 38(12): L12602

Smith RD, Dukowicz JK, Malone RC (1992) Parallel ocean general circulation modeling. Phys Nonlinear Phenom 60(1):38-61

Spencer H (2004) Role of the atmosphere in seasonal phase locking of El Niño. Geophys Res Lett 31(24):L24104

Suarez MJ, Schopf PS (1988) A delayed action oscillator for ENSO. J Atmos Sci 45:3283-3287
Valcke S, Caubel A, Declat D, Terray L (2003) Oasis3 ocean atmosphere sea ice soil user's guide. Prisim project report 2

Wang B, Zhang Q (2002) Pacific-East Asian teleconnection. Part II: how the Philippine Sea anomalous anticyclone is established during El Niño development. J Clim 15:3252-3265

Wang B, Wu R, Fu X (2000) Pacific-East Asian teleconnection: how does ENSO affect East Asian climate? J Clim 13(9):1517-1536

Weisberg RH, Wang C (1997) A western Pacific oscillator paradigm for the El Niño-Southern Oscillation. Geophys Res Lett 24(7):779-782

Wu R, Kirtman BP (2004) Understanding the impacts of the Indian Ocean on ENSO variability in a coupled GCM. J Clim 17(20): 4019-4031

Xiang B, Wang B, Ding Q, Jin FF, Fu X, Kim HJ (2012) Reduction of the thermocline feedback associated with mean SST bias in ENSO simulation. Clim Dyn 39(6):1413-1430

Xie SP, Hu K, Hafner J, Tokinaga H, Du Y, Huang G, Sampe T (2009) Indian Ocean capacitor effect on Indo-western Pacific climate during the summer following El Niño. J Clim 22(3):730-747

Yun KS, Yeh SW, Ha KJ (2013) Distinct impact of tropical SSTs on summer North Pacific high and western North Pacific subtropical high. J Geophys Res Atmos 118(10):4107-4116

Zhao X, Yuan D, Yang G, Zhou H, Wang J (2016) Role of the oceanic channel in the relationships between the basin/dipole mode of SST anomalies in the tropical Indian Ocean and ENSO transition. Adv Atmos Sci 33(12):1386-1400

Publisher's note Springer Nature remains neutral with regard to jurisdictional claims in published maps and institutional affiliations. 